\title{
Comparative characteristic of near-isogenic lines differing by the $B l p$ locus in respect to abiotic stress resistance
}

\author{
A.Y. Glagoleva ${ }^{1 *}$, O.Y. Shoeva ${ }^{1}$, E.K. Khlestkina ${ }^{1,2}$ \\ ${ }^{1}$ Institute of Cytology and Genetics, SB RAS, Novosibirsk, Russia \\ ${ }^{2}$ N.I. Vavilov All-Russian Research Institute of Plant Genetic Resources (VIR), St. Petersburg, Russia
}

DOI 10.18699/ICG-PlantGen2019-28

(c) Autors, 2019

* e-mail: glagoleva@bionet.nsc.ru

\begin{abstract}
The black color of seeds is a ubiquitous trait among plants. Black pigments are caused by polyphenolic polymeric compounds called melanins. The study of plant melanin is hampered because of its complex structure and chemical inertness. At the same time, an adaptive role of black pigments in unfavorable environments has been previously demonstrated. The aim of the current work was to compare near-isogenic barley lines carrying different alleles of the Blp locus controlling accumulation of melanins in the hull and grain pericarp under salinity, drought and cadmium toxicity. It was demonstrated that the lines did not differ in germination rate while they responded differently to stress exposures at the seedling stage. The pronounced decline in root and shoot length in the black-spiked line compared with the yellow-spiked one was observed under drought stress conditions, while under salinity and cadmium toxicity, slightly increased values of the relative shoot length of the black- and yellow-spiked lines were observed, respectively. The data obtained demonstrated that neither the Blp gene nor black pigmentation controlled by this gene confer any advantages on barley plants at the seedling stage under stress conditions tested.
\end{abstract}

Key words: melanin; grain; seedlings; germination; salinity; drought; cadmium toxicity.

\section{Introduction}

The black color of seeds associated with melanins has been described in many plant species (Britton, 1983). These pigments are formed by oxidation of phenolic compounds to quinones by polyphenol oxidases followed by their polymerization to black high molecular-weight polymers (Nicolas et al., 1994). Melanins accumulating in covering grain tissues reportedly strengthen seed envelopes and protect in this way the developing embryo against mechanical injury, affecting seeds' longevity and germination rate as well as confer an increased resistance on plants under pathogen invasions and unfavorable conditions (Rogers, Kreitner 1983; Duran, Retamal, 1989; Debeaujon et al., 2002; Downie et al., 2003; Loskutov et al., 2016).

In barley (Hordeum vulgare L.), the black-spiked genotypes with melanins accumulated in hull and grain pericarp were described (Harlan, 1914). The trait is under the control of the Blp locus, which was mapped on chromosome $1 \mathrm{H}$ (Costa et al., 2001). To date, the locus has been narrowed down to 21 genes, but the candidate gene has not been identified yet (Long et al., 2019).

Black-seeded barleys are considered to be more drought and cold tolerant, more vigorous at the early stages of growth, more prostrate, taller, earlier in maturity than yellow-seeded types (Ceccarelli et al., 1987) as well as more resistant to Fusarium diseases (Choo et al., 2005, 2015). Although the trait has agricultural importance, the precise chemical structure of plant melanins is far from being clear (Jana, 2014), as well as the genes associated with the biosynthesis of black pigments are still remain unknown. To determine the specific genes for melanin biosynthesis, it is important to fully understand features of the trait.

In the current study, a comparative analysis of near-isogenic lines (NILs) carrying different alleles of the Blp locus was performed to determine role of the Blp locus in grain germination as well as in the plant response to abiotic stresses at the seedlings stage.

\section{Materials and methods}

\subsection{Plant material}

The barley NILs i:BwBlp (NGB20470) with the black color of seeds and their parental cultivar 'Bowman' (NGB22812) characterized by uncolored seeds were used in the study. The lines were provided by the Nordic Gene Bank (NGB, www. nordgen.org) and previously genotyped by microsatellite markers. The only chromosome segment in $1 \mathrm{HL}$ was different in the lines (Druka et al. 2011; Shoeva et al., 2016).

\subsection{Germination test}

To compare the melanins impact on germination, the seeds were placed on filter paper moistened with distilled water and kept for $48 \mathrm{~h}$ at $4{ }^{\circ} \mathrm{C}$ without light to synchronize germination. Thereafter the seeds were transferred to a RUMED ${ }^{\circledR}$ climate chamber (Rubarth Apparate $\mathrm{GmbH}$ ) at $20^{\circ} \mathrm{C}$ and $12 \mathrm{~h} \mathrm{light} / 12 \mathrm{~h}$ darkness daily cycle. The start of germination, appearance of roots and shoots were observed. The experiment was performed in three replicates for each genotype, with one hundred seeds per replica. The seeds were harvested after the field vegetation season of 2016 and stored for two years at room temperature until tested.

\subsection{Stress exposure}

The comparative study of the NILs was performed at the seedling stage under laboratory conditions modeling salinity, drought and cadmium toxicity. Salt stress was induced by $\mathrm{NaCl}$ at eight different concentrations varying from 10 to $150 \mathrm{mM}$. To model the drought stress, the $15,20,30$, 
and $40 \%$ solutions of PEG6000 were used. Six concentrations of $\mathrm{CdCl}_{2}$ varying from 0.3 to $20 \mathrm{mM}$ were used in the experiment with cadmium stress. The seeds were placed on filter paper moistened with distilled water and kept for $48 \mathrm{~h}$ at $4{ }^{\circ} \mathrm{C}$ without light to synchronize germination. Thereafter the seeds were transferred to a RUMED ${ }^{\circ}$ climate chamber at $20^{\circ} \mathrm{C}$ and $12 \mathrm{~h} \mathrm{light} / 12 \mathrm{~h}$ darkness daily cycle. After $24 \mathrm{~h}$, the seeds were exposed to the corresponding stress treatment. Distilled water was added to the control. The experiment was performed in three replicates for each concentration and each genotype, with fifteen seeds per replica. The root and shoot lengths of each seedling were measured at the fifth day after germination. The significance of differences between the treated and control samples of the NILs was assessed using Student's $t$-test, taking $p \leq 0.05$ as significant. Changes in root and shoot lengths were calculated as follows: length under stress condition/length in control*100\%.

\section{Results and discussion}

\subsection{Germination test}

We have observed an earlier germination start in the $\mathrm{i}: \mathrm{Bw} B l p$ line compared to 'Bowman' $(p \leq 0.05)$. However, there were no significant differences between NILs in root and shoot appearance $(p>0.05)$, and subsequently differences in germination rate between the lines were not observed.

An effect of black pigments on seed germination had been reported previously. For instance, although the seed coat structure (epidermis, macrosclereid cells, pigmented cells and aleurone-like cells) did not differ significantly between red and black seeds of wild mustard, the germination of red seeds was higher than that of black seeds (Duran, Retamal, 1989). Tomato mutants accumulating melanins in testa displayed poor germination rates on both water and gibberellin compared with the wild-type seeds without the pigments (Downie et al., 2003). Although tests for germination rates performed on two-year-old grains did not reveal any differences between yellow and black grains of barley, the results did not deny the possibility that some differences could be detected after a longer period of dormancy. A similar germination rate of black and yellow grains allows using them in comparative studies under stress conditions.

\subsection{Stress exposure}

Osmotic stress was induced by different concentrations of $\mathrm{NaCl}$ and PEG6000. From among the concentrations tested, the ones that caused a significant reduction in root and shoot lengths compared with the control and were low enough to reveal differences between the NILs were selected for further experiments. The following concentrations were chosen: 50, 100 and $150 \mathrm{mM} \mathrm{NaCl}$ and 20, 30 and $40 \%$ PEG6000.

In the salt stress experiment, we observed that treatment by $\mathrm{NaCl}$ mostly affected the development of roots rather than shoots in both NILs (Figure 1,a). The root length varied from $40 \%$ to $70 \%$ relative to the control, while the shoot length did not fall below $70 \%$ relative to the control. We have revealed slight differences between the NILs in shoot length with an increased values in the $\mathrm{i}: \mathrm{Bw} B l p$ line at all salt concentrations tested, but not in root length.
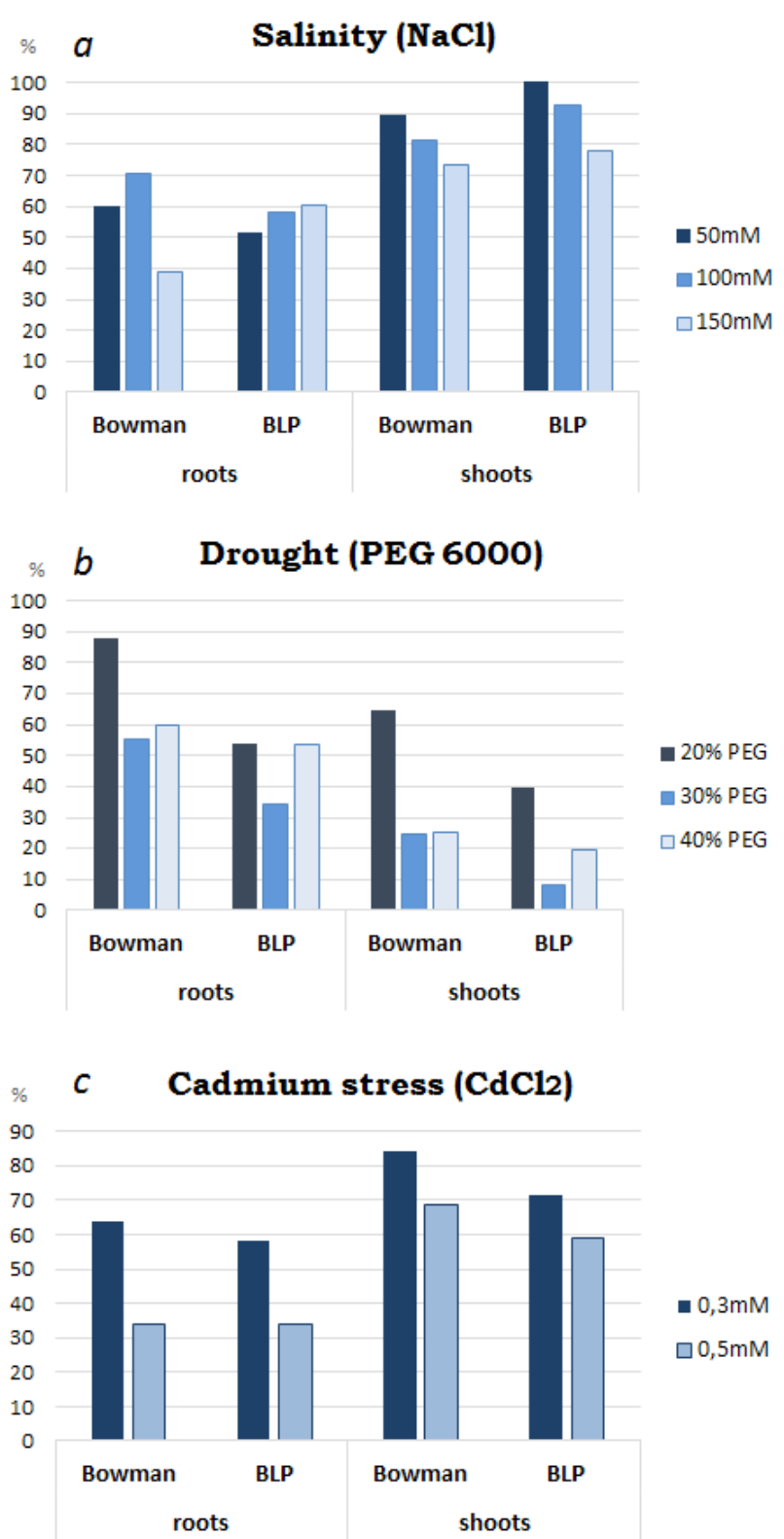

Figure 1. Changes in shoot and root length of 'Bowman' and $\mathrm{i} ; \mathrm{Bw} B / p$ (BLP) line under salinity (a), drought (b) and cadmium (c) relative to the control (\%).

In contrast to osmotic stress caused by $\mathrm{NaCl}$, PEG treatments affected mostly shoot growth in both NILs rather than roots (Figure 1,b). At 30 and $40 \%$ PEG concentrations, the shoot length was only $10-30 \%$ of the control, while the root length reached about $50 \%$ of the control in both 'Bowman' and i:BwBlp. Probably, there are different osmotic stress responsive mechanisms in the different parts of seedlings. A pronounced decline in seedling length in the i:BwBlp line compared with 'Bowman' was observed at all concentrations of PEG6000 tested with more drastic differences at $20 \%$ and $30 \%$ PEG, while under $40 \%$ they were not so strong.

To test the involvement of the Blp locus in cadmium stress resistance, 0.3 and $0.5 \mathrm{mM} \mathrm{CdCl}$ solutions were selected from among all the concentrations tested. Cadmium, similar 
to $\mathrm{NaCl}$, mostly affected root length rather than shoots under the same treatment conditions (Figure $1, c$ ). We observed a slight increment in relative root and shoot length in 'Bowman' compared to $\mathrm{i}: \mathrm{BwBlp}$. However, there were no significant differences between the NILs in absolute values.

The pigments present in seed envelopes can reportedly grant some advantages to plants under stress conditions. For instance, in comparative studies of the wheat NILs developed for grain anthocyanin pigmentation, it was demonstrated that at the seedling stage anthocyanins present in wheat grain positively affected roots elongation under drought conditions in comparison with non-pigmented line (Shoeva et al., 2017). The data obtained here demonstrated that neither the Blp gene nor black pigmentation controlled by this gene confer any advantages on barley plants at the seedling stage under stress conditions tested. Moreover, a pronounced decline in seedling length in the black-spiked line compared with the yellow-spiked one under PEG treatment was detected. Similar, susceptibility to water deficiency during germination and emergence was observed in Iraqi local barley cultivar 'Black' compared to yellow-grained cultivars, but it developed resistance during vegetation growth and yield formation (Yassen, Al-Omary, 1994). The data allows assuming the presence of a gene linked to Blp conferring drought resistance on 'Bowman' plants as well as Iraqi local barley cultivar mentioned.

\section{Conclusions}

Substances present in grain tissue not only can affect their germination but can also confer increased resistance under biotic and abiotic stress conditions. Using a precise genetic model of near-isogenic lines, we did not detect any significant positive effect of the dominant allele of the Blp gene on barley seedling growth or development under salinity, drought and heavy metal toxicity. These findings allow us to suggest that the $B l p$ locus affects specifically the pigmentation of barley spike, while it has no effect on plant development at the seedling stage even under stress conditions. This feature of the $B l p$ locus should be taken into account in further studies aimed at revealing a potential candidate gene for $B l p$.

\section{References}

Britton G. The biochemistry of natural pigments. Cambridge University Press. Cambridge. 1983.

Ceccarelli S., Grando S., van Leur J.A.G. Genetic diversity in barley landraces from Syria and Jordan. Euphytica. 1987;36:389-405. DOI 10.1007/BF00041482.

Choo T.M., Vigier B., Ho K.M., Ceccarelli S., Grando S., Franckowiak J.D. Comparison of black, purple, and yellow barleys. Genet. Resour. Crop. Evol. 2005;52(2):121-126. DOI 10.1007/s10722-0033086-4.

Choo T.-M., Vigier B.J., Savard M.E., Blackwell B.A., Martin R.A., Wang J.M., Yang J., Abdel-Aal E.-S.M. Black barley as a means of mitigating deoxynivalenol contamination. Crop Sci. 2015;55:10961103. DOI 10.2135/cropsci2014.05.0405.
Costa J.M., Corey A., Hayes P.M., Jobet C., Kleinhofs A., KopischObusch A., Kramer S.F., Kudrna D., Li M., Riera-Lizarazu O., Sato K., Szucs P., Toojinda T., Vales M.I., Wolfe R.I. Molecular mapping of the Oregon Wolfe Barleys: a phenotypically polymorphic doubled-haploid population. Theor. Appl. Genet. 2001; 103(2-3):415-424. DOI 10.1007/s001220100.

Debeaujon I., Léon-Kloosterziel K.M., Koornneef M. Influence of the testa on seed dormancy, germination, and longevity in Arabidopsis. Plant Physiol. 2000;122:403-414. DOI 10.1104/pp.122.2.403.

Downie A.B., Zhang D., Dirk L.M., Thacker R.R., Pfeiffer J.A., Drake J.L., Levy A.A., Butterfield D.A., Buxton J.W., Snyder J.C. Communication between the maternal testa and the embryo and/ or endosperm affect testa attributes in tomato. Plant Physiol. 2003; 133:145-160. DOI 10.1104/pp.103.022632.

Druka A., Franckowiak J., Lundqvist U., Bonar N., Alexander J., Houston K., Radovic S., Shahinnia F., Vendramin V., Morgante M., Stein N., Waugh R. Genetic dissection of barley morphology and development. Plant Physiol. 2011;155:617-627. DOI 10.1104/pp. 110.166249.

Duran J.M., Retamal N. Coat structure and regulation of dormancy in Sinapis arvensis L. seeds. J Plant Physiol. 1989;135:218-222. DOI 10.1016/S0176-1617(89)80180-4.

Harlan H.V. Some distinctions in our cultivated barleys with reference to their use in plant breeding. US Dept. of Agriculture. 1914;137:38.

Jana B.K., Mukherjee S.K. Notes on the distribution of phytomelanin layer in higher plants - a short communication. J. Pharmaceutical Biol. 2014;4(3):131-132.

Long Z., Jia Y., Tan C., Zhang X.-Q., Angessa T., Broughton S., Westcott S., Dai F., Zhang G., Sun D., Xu Y., Li C. Genetic Mapping and Evolutionary Analyses of the Black Grain Trait in Barley. Front. Plant Sci. 2019;9:1921. DOI 10.3389/fpls.2018.01921.

Loskutov I.G., Blinova E.V., Gavrilova O.P., Gagkaeva T.Yu. The valuable characteristics of oats genotypes and resistance to Fusarium disease. Vavilov J. Genet. Breed. 2016;20(3):286-294. DOI 10.18699/ VJ16.151.

Nicolas J.J., Richard-Forget F.C., Goupy P.M., Amiot M.J., Aubert S.Y. Enzymatic browning reactions in apple and apple products. Crit. Rev. Food Sci. Nutr. 1994;34(2):109-57. DOI 10.1080/1040839940 9527653

Rogers C.E., Kreitner G.L. Phytomelanin of sunflower achenes: a mechanism for pericarp resistance to abrasion by larvae of the sunflower moth (Lepidoptera: Pyralidae). Environ Entomol. 1983;12: 277-285. DOI 10.1093/ee/12.2.277.

Shoeva O.Y., Mock H.P., Kukoeva T.V., Börner A., Khlestkina E.K. Regulation of the flavonoid biosynthesis pathway genes in purple and black grains of Hordeum vulgare. PloS ONE. 2016;11(10):e0163782. DOI 10.1371/journal.pone.0163782.

Shoeva O.Yu., Gordeeva E.I., Abuzova V.S., Khlestkina E.K. Anthocyanins participate in protection of wheat seedlings from osmotic stress. Cereal Res. Commun. 2017;45:47-56. DOI 10.1556/0806. 44.2016.044

Yassen B.T., Al-Omary S.S. Analysis of the effects of water stress on leaf growth and yield of three barley cultivars. Irrig. Sci. 1994;14: 157-162. DOI 10.1007/BF00193138.

Acknowledgements. The study is supported by the Russian Science Foundation (Project No. 16-14-00086).

Conflict of interest. The authors declare no conflict of interest. 